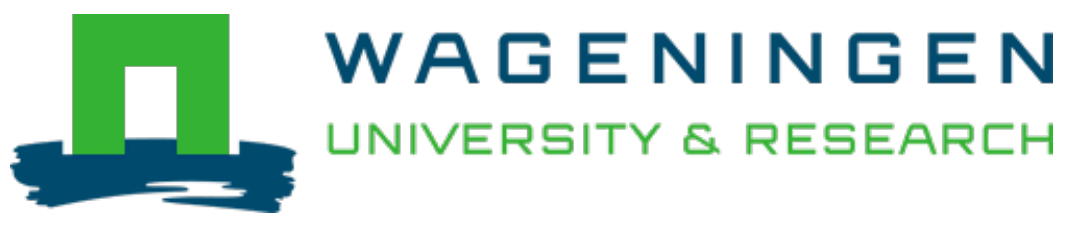

\title{
Microalgal nanosized polyphosphate bodies as novel iron supplements for iron- deficiency anemia treatment in rats
}

\author{
Food Bioscience \\ Gao, F.; Yu, M.; Guo, Wei; Zeng, Mingyong \\ https://doi.org/10.1016/j.fbio.2020.100834
}

This article is made publicly available in the institutional repository of Wageningen University and Research, under the terms of article $25 \mathrm{fa}$ of the Dutch Copyright Act, also known as the Amendment Taverne. This has been done with explicit consent by the author.

Article 25 fa states that the author of a short scientific work funded either wholly or partially by Dutch public funds is entitled to make that work publicly available for no consideration following a reasonable period of time after the work was first published, provided that clear reference is made to the source of the first publication of the work.

This publication is distributed under The Association of Universities in the Netherlands (VSNU) 'Article $25 \mathrm{fa}$ implementation' project. In this project research outputs of researchers employed by Dutch Universities that comply with the legal requirements of Article $25 \mathrm{fa}$ of the Dutch Copyright Act are distributed online and free of cost or other barriers in institutional repositories. Research outputs are distributed six months after their first online publication in the original published version and with proper attribution to the source of the original publication.

You are permitted to download and use the publication for personal purposes. All rights remain with the author(s) and / or copyright owner(s) of this work. Any use of the publication or parts of it other than authorised under article $25 \mathrm{fa}$ of the Dutch Copyright act is prohibited. Wageningen University \& Research and the author(s) of this publication shall not be held responsible or liable for any damages resulting from your (re)use of this publication.

For questions regarding the public availability of this article please contact openscience.library@wur.nl 


\title{
Microalgal nanosized polyphosphate bodies as novel iron supplements for iron-deficiency anemia treatment in rats
}

\author{
Fengzheng Gao ${ }^{\mathrm{a}, \mathrm{b}}$, Yu Miao ${ }^{\mathrm{c}}$, Wei Guo ${ }^{\mathrm{a}}$, Mingyong Zeng ${ }^{\mathrm{a},}$ \\ ${ }^{a}$ College of Food Science and Engineering, Ocean University of China, 5 Yushan Road, Qingdao, Shandong Province, 266003, China \\ ${ }^{\mathrm{b}}$ Wageningen University, Bioprocess Engineering, AlgaePARC, P.O. Box 16, 6700 AA, Wageningen, Netherlands \\ ${ }^{c}$ Department of Clinical Laboratory, The Affiliated Hospital of Qingdao University, Qingdao, Shandong Province, 266003, China
}

\section{A R T I C L E I N F O}

\section{Keywords:}

Polyphosphate bodies

Iron-deficiency anemia

Iron supplement

Hemoglobin regeneration efficiencies

Nanosized iron

\begin{abstract}
A B S T R A C T
Nanosized polyphosphate bodies (PPB) are potential iron supplements for iron deficiency treatment, which can be produced by microalgal cell factories. To investigate the effect of PPB on iron-deficiency anemia, irondeficient rats were constructed and given feeds with different iron supplements. Four iron supplements, i.e. PPB from microalgae, $\mathrm{FeSO}_{4}$, ferric citrate (FC), and synthetic polyphosphate (PolyP) + FC, were investigated in iron-deficiency anemia treatment at three different dietary intervention stages (i.e. day 3, 7, and 10). These four iron supplements showed similar hemoglobin ( $\mathrm{Hb}$ ) improvements at day 3 and 7, respectively; however, PPB and $\mathrm{FeSO}_{4}$ resulted in higher increased $\mathrm{Hb}$ and reticulocyte $\mathrm{Hb}$ than $\mathrm{FC}$ and PolyP at day 10 . The Hb regeneration efficiencies followed the order: PolyP $(42.6 \%) \approx \mathrm{FC}(47.7 \%)<\mathrm{FeSO}_{4}(56.1 \%) \approx \mathrm{PPB}(56.2 \%)$. The absolute reticulocyte content increased from day 3 to day 7 then decreased at day10 in all iron repletion groups. PPB diet supplied more intestinal total soluble, low-molecular weight, and nanosized iron than FC and PolyP diets. Overall, PPB are novel natural iron supplements that can be used for iron-deficiency anemia treatment, opened new possibilities to develop natural microalgal nanoparticles as high-value products in human health improvement.
\end{abstract}

\section{Introduction}

Iron deficiency is one of the most prominent global health risks for disability and death worldwide, affecting an estimated 2 billion people (Zimmermann \& Hurrell, 2007), remains the top-ranking cause of anemia worldwide (Clark, 2008). Iron-deficiency anemia has a substantial effect on humans, especially young children and women, in both developing and industrialised countries (Camaschella, 2015; McLean et al., 2009). Prevention programs have decreased rates of iron-deficiency anemia globally (Lundeen et al., 2019); the prevalence is now highest in Central and West Africa and South Asia (Kassebaum et al., 2015; Stevens et al., 2013). The prevalence of iron deficiency in developing countries is mainly caused by insufficient intakes and (or) poor availability of iron in plant-based diets that often contain inhibitors of iron digestion or absorption such as phytate (Lei et al., 2013). Paradoxically, it appears to be more difficult to reduce the prevalence of iron-deficiency anemia in industrialised countries than in developing countries due to the high rate of iron deficiency in aging populations (Kassebaum et al., 2015). Therefore, effective and sustainable interventions to control iron-deficiency anemia are needed urgently.

Dietary iron supplementation is the most commonly used strategy to decrease iron deficiency rate, suitable for large populations (Pritwani \& Mathur, 2015; Shrimpton \& Schultink, 2002). Several iron supplements, such as $\mathrm{FeSO}_{4}$, ferric citrate (FC), and $\mathrm{FeCl}_{3}$, were reported to be effective on iron-deficiency anemia (Block et al., 2015; Bries et al., 2019; Chaud et al., 2002; Ma et al., 2019). Among which, $\mathrm{FeSO}_{4}$ is commonly used as gold iron supplement. However, $\mathrm{FeSO}_{4}$ is easily oxidized and may have side effects for people with sensitive gut. The form of iron supplement is important due to its toxicity on the gastrointestinal system (Evcan \& Gulec, 2020). Therefore, discovering natural iron supplements is getting more and more important. In recent years, nanosized particles have obtained high attention in iron supplementation due to their high efficacy and absorption efficiency (Feng et al., 2020; Sharma et al., 2017; Wang et al., 2020). Nanosized particles can be captured by reticuloendothelial system, and dissolved into free iron, which is then made available for the organism (Alphandéry, 2019). For example, Rahmatollah et al. (2018) used cysteine-coated $\mathrm{Fe}_{3} \mathrm{O}_{4}$ nanoparticles $(1.2,12,120 \mathrm{mg} / \mathrm{kg})$ and $\mathrm{FeSO}_{4}(120 \mathrm{mg} / \mathrm{kg})$ as dietary iron

\footnotetext{
* Corresponding author.

E-mail address: mingyz@ouc.edu.cn (M. Zeng).
} 
supplements for quail. They found that $1.2 \mathrm{mg} / \mathrm{kg}$ cysteine-coated $\mathrm{Fe}_{3} \mathrm{O}_{4}$ nanoparticles were required and sufficient for quails' optimal maintenance and growth. In addition, Hilty et al. (2010) reported that a poorly water-soluble nanosized iron particle had in vivo iron bioavailability in rats comparable to $\mathrm{FeSO}_{4}$ and caused less colour change in reactive food matrices than conventional iron fortificants. Moreover, Wu et al. (2014) found nanosized ferric hydrolysis products prepared using muscle protein from Engraulis japonicus performed better than $\mathrm{FeSO}_{4}$ in the enhancement of non-heme iron absorption. All these showed the advantages for using nanosized particles as novel iron supplements. However, these mentioned nanosized particles were all artificial prepared, may have disadvantages of high preparation cost and low stability. Besides, toxic chemicals may be required in the preparation of synthetic nanoparticles. It has recently been suggested to follow natural synthesis methods, using plant extracts, fungus, yeast, or bacteria, to produce metallic nanosized particles (Alphandéry, 2020b, 2020d). These bio-synthesized particles are considered biocompatible and stable without side effects, which can be commercialized in improving human health (Hamdous et al., 2017).

Inorganic polyphosphate bodies (PPB; also known as volutin granules (Ruiz et al., 2001)) have recently been linked to a variety of functions in mammalian cells. PPB are nanosized structures contains large amounts of mineral elements with polyphosphate (PolyP) as basic structural composition (Gao et al., 2018). In recent years, its functions in health improvement are getting realized. Segawa et al. (2011) reported that extracted PolyP from PPB in Lactobacillus brevis SBC8803 enhanced F-actin stability of human colonic epithelial Caco2/BBE cells, and improved intestinal injury and survival rate of mice treated with a lethal dose of dextrin sodium sulfate. In addition, Feng et al. (2018) reported that PPB was potential in exhibit intestinal protective in human intestinal cells. Moreover, they found that PPB could enhance the intestinal barrier function by upregulating the colonic expressions of heat shock protein 25 and tight junction proteins (Feng et al., 2019). The effect of PPB on intestinal function improvement is clear; however, the research of PPB in mineral supplementation is still missing. As natural iron carriers, PPB could be used as iron supplements. The effect of PPB on iron deficiency improvement is worthy of investigation.

Microalgae are sunlight-driven cell factories that convert carbon dioxide to various high value products, including PPB (Gao et al., 2018; Wijffels \& Barbosa, 2010). Synechococcus sp. PCC 7002 is a green microalgal cell factory for PPB production with a fast growth rate. PPB extracted from Synechococcus sp. PCC 7002 are natural nanosized particles that can be produced in industrial scale. Moreover, high-iron PPB can be produced by increasing iron concentration in the cultivation medium. All these make microalgal PPB more competitive nanosized particles than artificial prepared ones.

In the present study, we aimed to identify the effect of PPB as iron supplement on the treatment of iron-deficient anemia. To do this, irondeficient rats were constructed and given $\mathrm{PPB}, \mathrm{FeSO}_{4}, \mathrm{FC}$, and synthetic PolyP + FC to subdue the deficiency. Afterwards, the hemoglobin $(\mathrm{Hb})$ regeneration, reticulocyte, liver and spleen iron were measured to assess the effect of iron repletion. Hb regeneration efficiencies and intestinal iron species were analysed to evaluate the enhancement of iron absorption by PPB. To investigate the effects at different intervention time, all mentioned measurements, except intestinal iron species (measured only at day 10), were carried out at day 3,7 , and 10 , respectively. This study not only provides evidence for developing PPB as novel iron supplements, but also supplies idea for high-value processing and utilization of microalgal biomass.

\section{Materials and methods}

\subsection{Materials}

Microalgal biomass of Synechococcus sp. PCC 7002 was produced in 20 L plastic photobioreactors with medium A (Ludwig \& Bryant, 2011) at $32{ }^{\circ} \mathrm{C}$ under a continuous illumination at light intensity of $100 \mu \mathrm{mol}$ $\mathrm{m}^{-2} \mathrm{~s}^{-1} \cdot \mathrm{FeCl}_{3} \cdot 6 \mathrm{H}_{2} \mathrm{O}$, obtained from Sinopharm Chemical Reagent Co. (Shanghai, China), was added $(0.29 \mu \mathrm{M})$ in the cultivation medium for iron accumulation in PPB. Sprague-Dawley (SD) rats were obtained from Shandong Lukang Pharmaceutical Group Co., Ltd. (Jining, Shandong, China). Pelletized purified AIN-93G based diets (comprised 397 $\mathrm{g} / \mathrm{kg}$ cornstarch, $200 \mathrm{~g} / \mathrm{kg}$ casein, $132 \mathrm{~g} / \mathrm{kg}$ dextrinized cornstarch, 100 $\mathrm{g} / \mathrm{kg}$ sucrose, $70 \mathrm{~g} / \mathrm{kg}$ soybean oil, $50 \mathrm{~g} / \mathrm{kg}$ fibre, $35 \mathrm{~g} / \mathrm{kg}$ mineral mix and $10 \mathrm{~g} / \mathrm{kg}$ vitamin mix) were prepared by TROPHIC Animal Feed High-tech Co., Ltd. (Nantong, Jiangsu, China). Sodium polyphosphate (PolyP) was obtained from Merck KGaA (Darmstadt, Germany).

\subsection{Methods}

\subsubsection{Polyphosphate bodies preparation and iron content measurement}

PPB was extracted from Synechococcus sp. PCC 7002 and purified according to the previous reported method (Gao et al., 2018). The water solution of purified PPB was concentrated 20 times using a $5 \mathrm{kDa}$ ultrafiltration membrane (PXB005A50, Millipore, Boston, MA, USA). The purified PPB was observed under transmission electron microscopy (TEM; JEM-2100Plus JEOL, Tokyo, Japan) according to the reported method (Gao et al., 2018). The energy dispersive X-ray spectroscopy was performed using the same TEM to analyse the elements composition of PPB. To measure the iron content in concentrated PPB solution, $5 \mathrm{~mL}$ PPB was digested based on the reported method (Gao et al., 2019). The iron standard was bought from General Research Institute for Nonferrous Metals (Beijing, China) and was diluted into concentrations of 1, 2, $4,6,8,10 \mathrm{mg} / \mathrm{L}$, respectively, with $1 \%$ nitric acid. The calibration curve and content of iron were measured in triplicate by Atomic Absorption Spectroscopy (AAS; AA-6880, Shimadzu, Tokyo, Japan). The PPB solution was stored at $-20^{\circ} \mathrm{C}$.

\subsubsection{Feeds preparation and iron in feeds analysis}

The iron content in standard AIN-93G feed is $\approx 35 \mathrm{mg} / \mathrm{kg}$. The Fedeficient diet contained $\approx 6 \mathrm{mg} / \mathrm{kg}$ iron derived from raw materials. The Fe-sufficient diet contained $\approx 30 \mathrm{mg} / \mathrm{kg}$ iron in the form of FC and $\approx 6 \mathrm{mg} / \mathrm{kg}$ iron derived from raw materials. The Fe-repletion diets contained $\approx 6 \mathrm{mg} / \mathrm{kg}$ iron derived from raw materials and $\approx 30 \mathrm{mg} / \mathrm{kg}$ iron in the forms of $\mathrm{FeSO}_{4}, \mathrm{FC}, \mathrm{PPB}$, and PolyP $+\mathrm{FC}$. $\mathrm{FeSO}_{4}$ served as the positive control group while $\mathrm{FC}$ served as the negative control group. To prepare PPB feed, $562 \mathrm{~mL}$ concentrated PPB solution was added to $1 \mathrm{~kg}$ AIN-93G Fe-deficient diet. The amount of PolyP in PPB solution was quantified according to the reported method (Gao et al., 2018). The equal amount of synthetic PolyP (161 mg/kg) as PPB group was added to standard AIN-93G feed to serve as a reference group, namely PolyP group. Feeds were dried with temperature below $40^{\circ} \mathrm{C}$. The iron content in the feed was measured using AAS (Shimadzu) as the methods mentioned above.

\subsection{Animal experiments}

All animal handling was conducted in accordance with National Institutes of Health guide for the care and use of Laboratory animals (NIH Publications No. 8023, revised 1978) and approved by the Ethical Committee of Animal Care and Use at Ocean University of China (Permit 20001013).

The iron bioavailability was measured in anemic rats using a $\mathrm{Hb}$ regeneration bioassay (Hilty et al., 2010; Mahoney et al., 1974). The weaning male SD rats received Fe-deficient diet and Milli-Q water ad libitum for iron deficiency model construction. The $\mathrm{Hb}$ concentration was measured after 10 days' Fe-deficient diet feeding by tail vein bleeding. The Fe-deficient SD rats were transferred into individual stainless-steel cages under controlled conditions at temperature of $22 \pm$ $2{ }^{\circ} \mathrm{C}$ and relative humidity of $55 \pm 10 \%$ with a day/night cycle of $12 / 12$ $\mathrm{h}$ and were randomly assigned into Fe-deficient, $\mathrm{FeSO}_{4}, \mathrm{FC}, \mathrm{PPB}$, and PolyP groups. Fe-deficient group contains 8 rats while each iron 
repletion group contains 12 rats. Another 6 SD rats received standard AIN-93G diet and Milli-Q water ad libitum throughout the experiments from the beginning, served as the normal control (Con) group. Rats from different groups received the corresponding feed for 10 days. Rats in Fe-deficient group received Fe-deficient diet throughout the experiment. A known and adequate amount of a diet was given to a rat in the feeding container between 9:00 and 10:00 a.m. The diet remaining in the feeding container and at the bottom of the cage was reweighed after 24 $\mathrm{h}$; the daily food consumption of each rat was calculated, and body weight (BW) was counted every day. Blood samples were collected by abdominal aortic method from 4 rats at day 3, 7 and 10, respectively, in each iron repletion group. Blood samples were collected at the end of the repletion period (day 10) in Con and Fe-deficient groups. The rats were anesthetized with ether before their livers and spleens were taken. Liver and spleen samples were taken from 4 rats in each group at day 3, 7 and 10 , respectively, and were rinsed with saline, frozen with liquid nitrogen rapidly and stored at $-80^{\circ} \mathrm{C}$.

\subsubsection{Hemoglobin, reticulocyte, liver and spleen iron measurement}

Blood samples ( $500 \mu \mathrm{L}$ with sodium citrate as anticoagulation) were sent to The Affiliated Hospital of Qingdao University (Qingdao, Shandong, China) within $1 \mathrm{~h}$ for $\mathrm{Hb}$ content, reticulocyte concentration and reticulocyte $\mathrm{Hb}$ content measurements using CELL-DYN 1600 (Abbott Diagnostics, Lake Bluff, IL, USA). The livers and spleens were dried in the oven at $100^{\circ} \mathrm{C}$ for $24 \mathrm{~h}$. Approximate $0.5 \mathrm{~g}$ of the liver and the whole spleen were weighted and digested for iron concentration measurement, respectively, according to the method mentioned above using AAS (Shimadzu).

\subsection{Intestinal iron species analysis}

Iron speciation analysis of rat intestinal contents was carried out as the previously reported method in the end of the experiment at day 10 (Wu et al., 2014). The rats were fasted for $9 \mathrm{~h}$ and then fed with different Fe-repletion diets for $30 \mathrm{~min}$ ad libitum and were anesthetized with ether (Sinopharm Chemical Reagent) at $90 \mathrm{~min}$ after diet consumption. The rats were killed after blood collection, an abdominal midline incision was performed before. After the small intestine was removed from the carcass, the content in the proximal one-third segment was flushed with $12 \mathrm{~mL}$ saline into a $15 \mathrm{~mL}$ sterile centrifuge tube and further fractionated into two fractions using Millipore filters (Merck KGaA): the $0.22 \mu \mathrm{m}$ filter and the $3 \mathrm{kDa}(\approx 1 \mathrm{~nm})$ filter, corresponding to total soluble iron and low-molecular weight (LMW) iron, respectively. Iron concentrations in the intestinal content, $0.22 \mu \mathrm{m}$ filtered fraction and 3 $\mathrm{kDa}$ filtered fraction were determined by flame atomic absorption spectroscopy using an AAS (Shimadzu) based on the method mentioned above.

\subsection{Calculations}

$\mathrm{Hb}$ iron pool (mg), assuming a total rat blood volume of $6.70 \% \mathrm{BW}$ and an iron content in $\mathrm{Hb}$ of $0.335 \%$ (Mahoney et al., 1974), was calculated as Equation (1).

$\mathrm{Hb}$ iron pool $=\mathrm{BW} \times 0.067 \times C_{\mathrm{Hb}} \times 3.35$

where BW was the measured body weight $(\mathrm{kg})$ and $C_{\mathrm{Hb}}$ was the measured blood $\mathrm{Hb}$ concentration $(\mathrm{g} / \mathrm{L})$.

$\mathrm{The} \mathrm{Hb}$ regeneration efficiency (\%) was calculated by using the Equation (2). where final and initial $\mathrm{Hb}$ iron pool $(\mathrm{mg})$ were the $\mathrm{Hb}$ iron pool at blood collection day $(3,7,10)$ and day 0 , repetitively, and total consumed iron was the total iron supplementation amount $(\mathrm{mg})$ from the diet.

The percentage of the total soluble iron (\%) in intestinal content was calculated by using the Equation (3).

Total soluble iron $=0.22 \mu \mathrm{m}$ filtrate iron $/$ intestinal iron $\times 100$

where $0.22 \mu \mathrm{m}$ filtrate iron was the iron concentration $(\mathrm{mg} / \mathrm{kg})$ in 0.22 $\mu \mathrm{m}$ filtered fraction and intestinal iron $(\mathrm{mg} / \mathrm{kg}$ ) was the measured iron concentration in intestinal content.

The percentage of the LMW iron (\%) in intestinal content was calculated by using the Equation (4).

LMW iron $=3 \mathrm{kDa}$ filtrate iron / intestinal iron $\times 100$

where $3 \mathrm{kDa}$ filtrate iron was the iron concentration $(\mathrm{mg} / \mathrm{kg})$ in $3 \mathrm{kDa}$ filtered fraction and intestinal iron $(\mathrm{mg} / \mathrm{kg}$ ) was the measured iron concentration in intestinal content.

The percentage of nanosized iron (\%) in intestinal content was calculated by using the Equation (5).

Nanosized iron $=$ Total soluble iron - LMW iron

\subsection{Statistical analysis}

Experimental results were expressed as mean value \pm standard deviation (SD). Differences between groups were tested for significance by the least significant difference mean comparison using the IBM ${ }^{\circledR}$ SPSS ${ }^{\circledR}$ Statistics software program (version 25, SPSS Inc., Chicago, IL, USA). The relationship between variables was determined by one-way ANOVA at a significance level of 0.05 using a Duncan Post-Hoc test.

\section{Results and discussion}

\subsection{Iron analysis in $P P B$}

PPB were observed under TEM as nanosized particles within $100 \mathrm{~nm}$ shown as black spots (Fig. 1a). The energy dispersive X-ray spectroscopy showed that PPB contains several mineral elements (Fig. 1b). Among these elements, $\mathrm{K}, \mathrm{Ca}, \mathrm{Mg}$, and $\mathrm{Fe}$ are major minerals in PPB. As microelement in human bodies, iron is one of the most valuable mineral elements in PPB, playing important roles in human health. Two iron signals at $0.7 \mathrm{keV}$ and $6.4 \mathrm{keV}$ were found on the energy dispersive spectrum corresponding to $L \alpha, K \alpha$ spectral lines (Fig. 1b). However, iron $\mathrm{K} \beta$ spectral line was not detected in the present study due to the weak signal around $7.1 \mathrm{keV}$. The major elements showed in the spectrum were C, $\mathrm{O}$ and $\mathrm{Cu}$ (Fig. 1b). $\mathrm{C}$ and $\mathrm{O}$ are the basic structural elements of PPB while $\mathrm{Cu}$ signal was mainly from the material of supporting gridding for TEM. Besides these three major elements, P signal was significantly higher than other elements (Fig. 1b), which came from PolyP (the basic composition of $\mathrm{PPB}$ ).

PPB were reported as minerals storage particles in microorganisms in several previous studies. For instance, Penen et al. (2016) reported the presence of elements $\mathrm{Ca}, \mathrm{P}, \mathrm{K}, \mathrm{Fe}$, and $\mathrm{Zn}$ in PPB in the unicellular green algae Chlamydomonas reinhardtii. In addition, Zhou et al. (2017) observed large amount of iron in PPB in a genetic improved Magnetospirillum gryphiswaldense strain. Moreover, Li et al. (2019) classified five metal-types of PPB, including Mg-type, Mg, Na-type, Mg, K-type, Mg, K, Na-type, and $\mathrm{Mg}, \mathrm{K}, \mathrm{Na}$, Ca-type, in enhanced biological phosphorus removal systems containing various of microorganisms. Iron was 
a

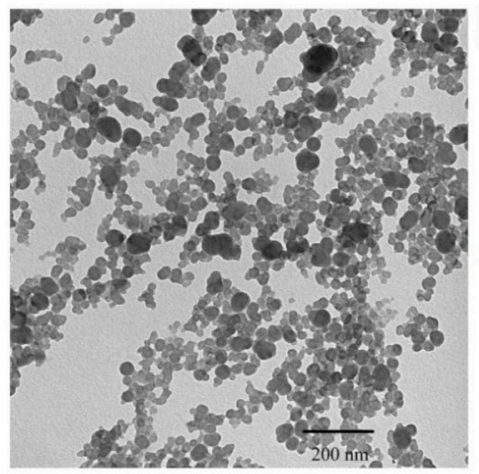

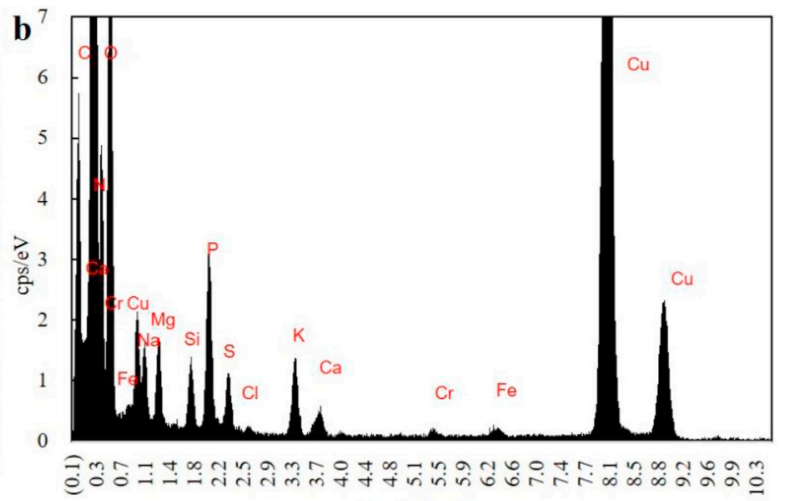

Energy keV

Fig. 1. Transmission electron microscopy observation (a) and energy dispersive X-ray spectroscopy (b) of PPB.

generally formed as $\mathrm{Fe}_{3} \mathrm{O}_{4}$ in nanosized particles obtained from biomineralization (Alphandéry, 2020a; Rahn-Lee \& Komeili, 2013). Synthesized nanoparticles $\left(\mathrm{Fe}_{3} \mathrm{O}_{4} @\right.$ APS NPs) have good water solubility and stability, especially in imitated digestion (Wang et al., 2019). In the present study, PPB also showed high water solubility and stability. Compared to synthesized nanoparticles, the mineral elements in PPB can be changed by changing cultivation conditions. Microalgae, especially Synechococcus sp. PCC 7002, are sustainable cell factories for PPB production and can be genetically improved for PPB overproduction (Gao et al., 2018).

\subsection{Iron analysis in feeds}

The PolyP content in concentrated PPB water solution was $286 \pm$ $7.21 \mathrm{mg} / \mathrm{L}$, and the iron content was $44.5 \pm 2.22 \mathrm{mg} / \mathrm{L}$ (data not shown). The PolyP content increased $60.7 \%$ as increasing iron $\left(\mathrm{FeCl}_{3}\right)$ concentration from 0.14 to $0.29 \mu \mathrm{M}$ in the medium, meaning PPB with different iron contents can be produced by changing iron concentration in the medium. The drying time of the PPB feed was almost double as FC and $\mathrm{FeSO}_{4}$ feeds due to presence of abundant PolyP with strong water hold capacity (SHULTS \& WIERBICKI, 1973). The iron contents (dry weight basis) in different feeds were shown in Table 1. The iron content of Fe-deficient feed was $5.64 \mathrm{mg} / \mathrm{kg}$ which was lower than that $(10 \mathrm{mg} / \mathrm{kg})$ reported by Wu et al. (2014) and similar to the result obtained by Alferez et al. (2011), depending on feed processing with different raw materials. The iron content in Con group was significantly higher than that in PPB group. The iron contents were similar in iron repletion groups without significant differences ( $p>0.05$ ), meaning rats in different groups received comparable diet with identical iron content.

\section{3. $\mathrm{Hb}$ regeneration bioassay analysis}

The initial BW (93.9-116 g) in all iron repletion groups were similar without significant differences (Table $1 ; \mathrm{p}>0.05$ ). The diet intake showed no significant differences in different iron repletion groups at the same day ( $\mathrm{p}>0.05$ ). However, the diet intake was significantly lower in Fe-deficient group and higher in Con group than these in iron repletion groups at day 10 (Table $1 ; p<0.05$ ). Iron deficiency caused negative effect on rat in appetite and body growth. No significant differences were found in BW gain in iron repletion groups at the same day, except FC group, showing a slightly lower BW gain at day $10(\mathrm{p}<0.05)$.

The initial $\mathrm{Hb}$ contents were similar without significant differences in all iron repletion groups (Table $1 ; \mathrm{p}>0.05$ ), meaning all groups had similar initial iron deficiency levels. The $\mathrm{Hb}$ content decreased further by $7.40 \mathrm{~g} / \mathrm{L}$ in the Fe-deficient group due to the continuous feeding of Fe-deficient diet. No significant differences were found in $\mathrm{Hb}$ changes (increased by $7.50-11.3 \mathrm{~g} / \mathrm{L}$ ) in all Fe repletion groups at day 3 (Table 1; $\mathrm{p}>0.05)$. The $\mathrm{Hb}$ increase in PolyP group was significantly lower than these in other groups at day 7 ( $p<0.05$ ) (Table 1 ). In the end of the diet intervention (day 10), the $\mathrm{Hb}$ changes were similar in $\mathrm{PPB}$ and $\mathrm{FeSO}_{4}$ groups, which were higher than these in FC and PolyP groups.

Interestingly, the $\mathrm{Hb}$ changes were similar in all iron repletion groups despite different supplement forms at early repletion stage. After iron depletion, the rats had a serious problem of iron deficiency with $\mathrm{Hb}$ contents only $33 \%$ as in Con group. The forms of iron supplements did not affect the absorption efficiency in this situation since major iron can be used by rats. However, $\mathrm{PPB}$ and $\mathrm{FeSO}_{4}$ showed better performances at the end of the repletion (day 10) when iron deficiency was already improved, which indicated that $\mathrm{PPB}$ and $\mathrm{FeSO}_{4}$ have advantages in iron deficiency improvement especially in mild iron deficiency situations.

$\mathrm{The} \mathrm{Hb}$ regeneration efficiency was in line with $\mathrm{Hb}$ changes. It was lower in PolyP group (29.6-42.6\%) during the whole period than in other groups (Table $2 ; \mathrm{p}<0.05$ ). The $\mathrm{Hb}$ regeneration efficiencies were similar in $\mathrm{FeSO}_{4}, \mathrm{FC}$ and $\mathrm{PPB}$ groups at day 3 and 7 ( $\left.\mathrm{p}>0.05\right)$. However, $\mathrm{FeSO}_{4}$ and PPB resulted in a higher $\mathrm{Hb}$ regeneration efficiency $(\approx 56 \%)$ than FC and PolyP groups at day 10 (Table 2; p < 0.05). The $\mathrm{Hb}$ regeneration efficiency increased from day $3-10$ in all groups, meaning the iron conversion efficiency from diet to $\mathrm{Hb}$ increased when iron deficiency was improved.

$\mathrm{FeSO}_{4}$ is the most commonly used iron supplement in iron-deficiency anemia treatment as a gold standard (Bries et al., 2019; Rahmatollah et al., 2018) while FC was the original iron supplement in standard AIN-93G feed. Block et al. (2015) reported the effect of FC on the treatment of iron deficiency anemia in 149 patients. They found FC increased $\mathrm{Hb}$ levels from 105 to $110 \mathrm{~g} / \mathrm{L}$ in 12 days treatment. The increased $\mathrm{Hb}$ content was larger in the present study due to a lower initial $\mathrm{Hb}$ content. The iron supplementation in PolyP group was also from FC. The lower $\mathrm{Hb}$ regeneration efficiency in PolyP group indicated that synthetical PolyP itself did not affect iron absorption. Hence, PPB improved iron-deficiency anemia as whole nanosized particles containing PolyP and iron together. FC can also improve iron deficiency anemia but had a lower regeneration efficiency compared with PPB and $\mathrm{FeSO}_{4}$. Overall, PPB showed a promising effect on iron-deficiency anemia improvement.

\subsection{The reticulocyte $\mathrm{Hb}$ content measurement}

Reticulocytes are the youngest erythrocytes released from the bone marrow into circulating blood. The reticulocyte $\mathrm{Hb}$ content is a predictive biomarker of iron deficiency and important in clinical diagnosis (Ennis et al., 2018; Gastroenterol et al., 2018). The reticulocyte $\mathrm{Hb}$ content was the highest in Con group while the lowest in Fe-deficiency group (Fig. 2). The reticulocyte $\mathrm{Hb}$ content in Fe-deficiency group was $45.5 \%$ as that in Con group, meaning a serious iron deficiency level. For all groups, the reticulocyte $\mathrm{Hb}$ content increased from day 3 to day 10 and were higher than that in Fe-deficiency group, showing 


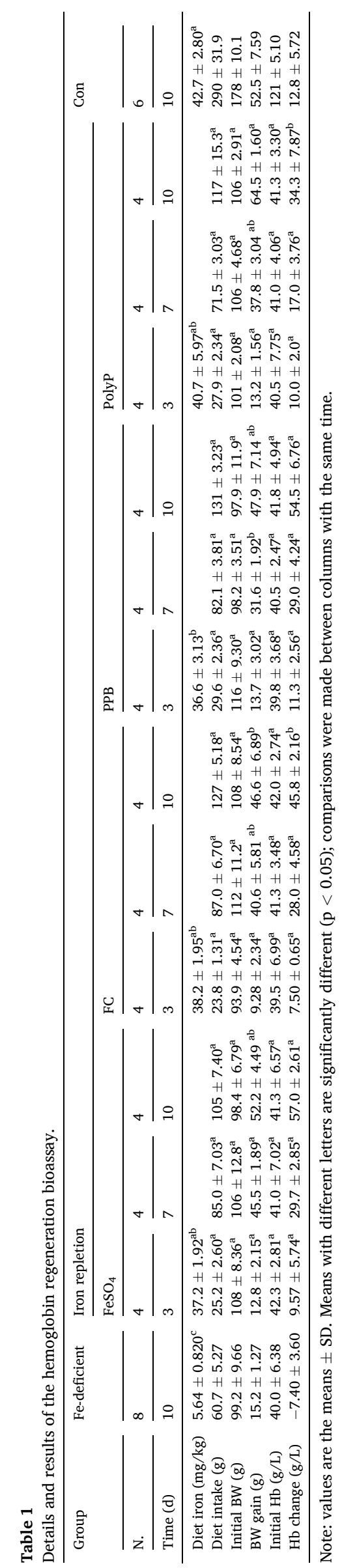

improvements of iron-deficiency. In the end of iron repletion, the reticulocyte $\mathrm{Hb}$ contents in $\mathrm{FeSO}_{4}$ and $\mathrm{PPB}$ groups were similar without significant differences $(p>0.05)$ and were significantly higher than those in FC and PolyP groups ( $\mathrm{p}<0.05$ ). The reticulocyte $\mathrm{Hb}$ contents in $\mathrm{FeSO}_{4}$ and PPB groups were lower than in Con group at day 10, meaning the rats were still iron deficient. The 10 days' dietary intervention was too short for rats to get rid of iron deficiency anemia completely.

\subsection{Absolute reticulocyte content analysis}

The absolute reticulocyte content is another important predictor of iron-deficiency anemia (Gezgin Yildırım et al., 2019; Parodi et al., 2016). The absolute reticulocyte content in Con group was significantly higher than that in Fe-deficiency group (Fig. 3; p < 0.05). The absolute reticulocyte contents in all iron repletion groups were significantly higher than that in Con group (Fig. $3 ; \mathrm{p}<0.05$ ), indicating stronger hematopoietic capacities in bone marrow. It increased from day 3 to day 7 then decreased at day10 in all iron repletion groups (Fig. 3). It decreased at day 10 due to the improvement of iron deficiency. The absolute reticulocyte contents of iron repletion groups were 1.6-2.5 times higher than that in Con group at day 10, indicating the hematopoiesis in bone marrow was still active. Wu et al. (2019) reported a similar finding of higher absolute reticulocyte contents in iron deficient rats after iron repletion for 24 days. However, they only measured it at the last day of the iron depletion. To our best knowledge, it is the first time for reticulocyte analysis to be reported at different iron repletion stage in rats, which supplied information for dynamic effects of iron supplements on iron deficiency improvement.

\subsection{Liver and spleen iron analysis}

Liver is considered as the major iron storage organ in human body, playing important roles in iron absorption and regulation (Lesjak et al., 2019; Pietrangelo, 2016). The liver iron in Con group was the highest, which was 5.9-fold as that in Fe-deficiency group. The liver iron contents at different iron repletion time in all iron repletion groups were significantly lower $(\approx 50 \%)$ than that in Con group (Fig. 4 ; $\mathrm{p}<0.05)$. A slightly higher liver iron content was observed in $\mathrm{FeSO}_{4}$ and $\mathrm{PPB}$ groups than these in FC and PolyP groups but without significant differences ( $\mathrm{p}$ $\square 0.05$ ). The lower liver iron content in all iron repletion groups indicated the rats were still at the stage of blood iron accumulation. Hence, the performance of different iron supplements can be assessed by analysing $\mathrm{Hb}$ regeneration efficiency in the previous section.

Spleen is another iron storage organ that contains large amount of deposited iron in iron-storage proteins (Alenkina et al., 2019). The trends of spleen iron contents were similar to liver iron. However, the increases of spleen iron were higher than liver iron increases from day 3 to day 10. The spleen iron contents were similar without significant differences in all iron repletion groups at day 3 (Fig. 5; p > 0.05), corresponding to approximately $55 \%$ of the spleen iron in Con group. The spleen iron in PPB and $\mathrm{FeSO}_{4}$ groups increased by $71.0 \%$ and $53.7 \%$, respectively, from day 3 to day 10 . The final spleen iron contents in PPB and $\mathrm{FeSO}_{4}$ groups were similar without significant differences (Fig. 5; p $\square 0.05$ ), reaching $77.0 \%$ as that in Con group. The increases of spleen

Table 2

Hemoglobin regeneration efficiency at different iron repletion stages.

\begin{tabular}{llll}
\hline \multirow{2}{*}{ Group } & \multicolumn{3}{l}{ Hb regeneration efficiency (\%) } \\
\cline { 2 - 4 } & Day 3 & Day 7 & Day 10 \\
\hline $\mathrm{FeSO}_{4}$ & $34.3 \pm 2.15^{\mathrm{a}}$ & $43.4 \pm 6.19^{\mathrm{a}}$ & $56.1 \pm 2.48^{\mathrm{a}}$ \\
$\mathrm{FC}$ & $37.4 \pm 1.98^{\mathrm{a}}$ & $38.8 \pm 4.54^{\mathrm{ab}}$ & $47.7 \pm 2.71^{\mathrm{b}}$ \\
$\mathrm{PPB}$ & $39.3 \pm 3.13^{\mathrm{a}}$ & $42.2 \pm 4.04^{\mathrm{a}}$ & $56.2 \pm 3.10^{\mathrm{a}}$ \\
PolyP & $29.6 \pm 4.34^{\mathrm{b}}$ & $34.4 \pm 0.880^{\mathrm{b}}$ & $42.6 \pm 4.55^{\mathrm{b}}$ \\
\hline
\end{tabular}

Note: values are the means \pm SD. Means with different letters are significantly different $(\mathrm{p}<0.05)$. 


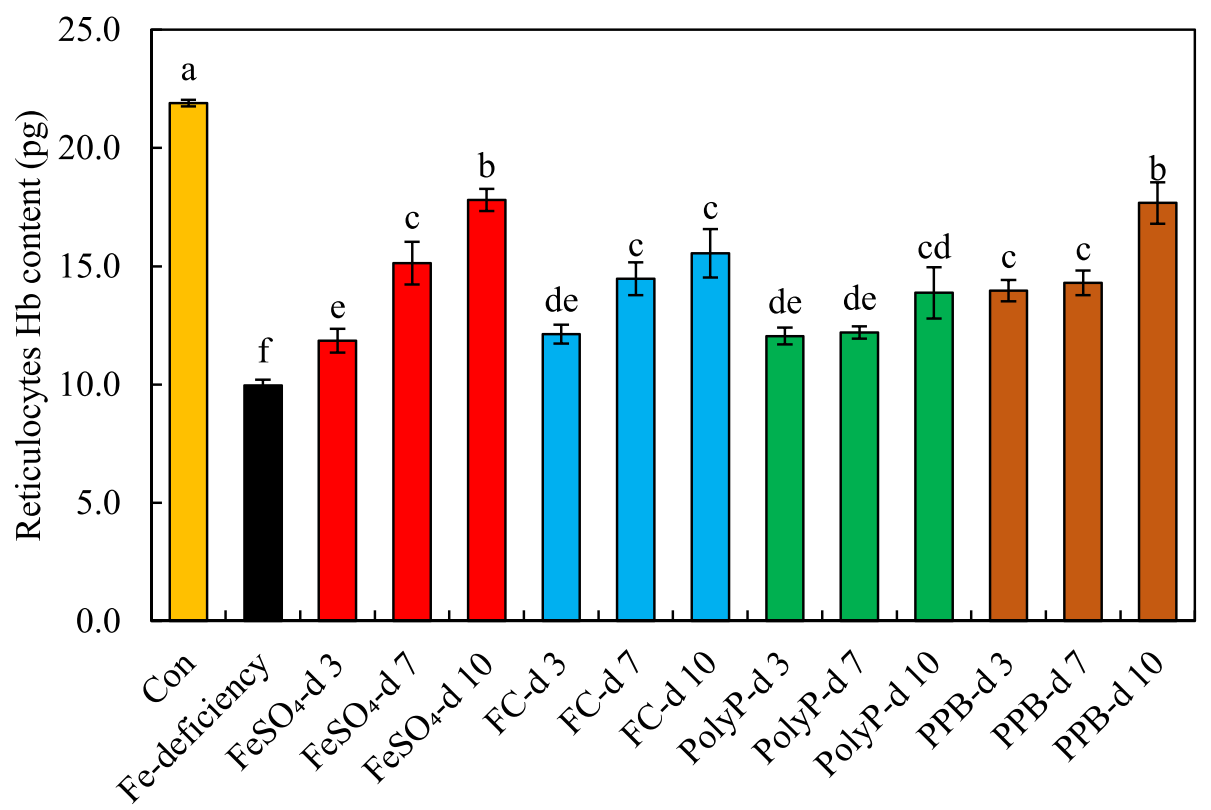

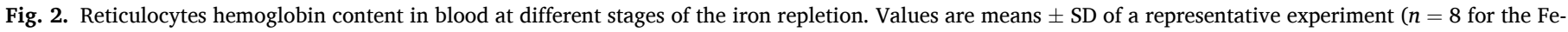
deficiency group; $n=6$ for the Con group; $n=4$ for other groups). Bars with different letters are significantly different (p $<0.05$ ).

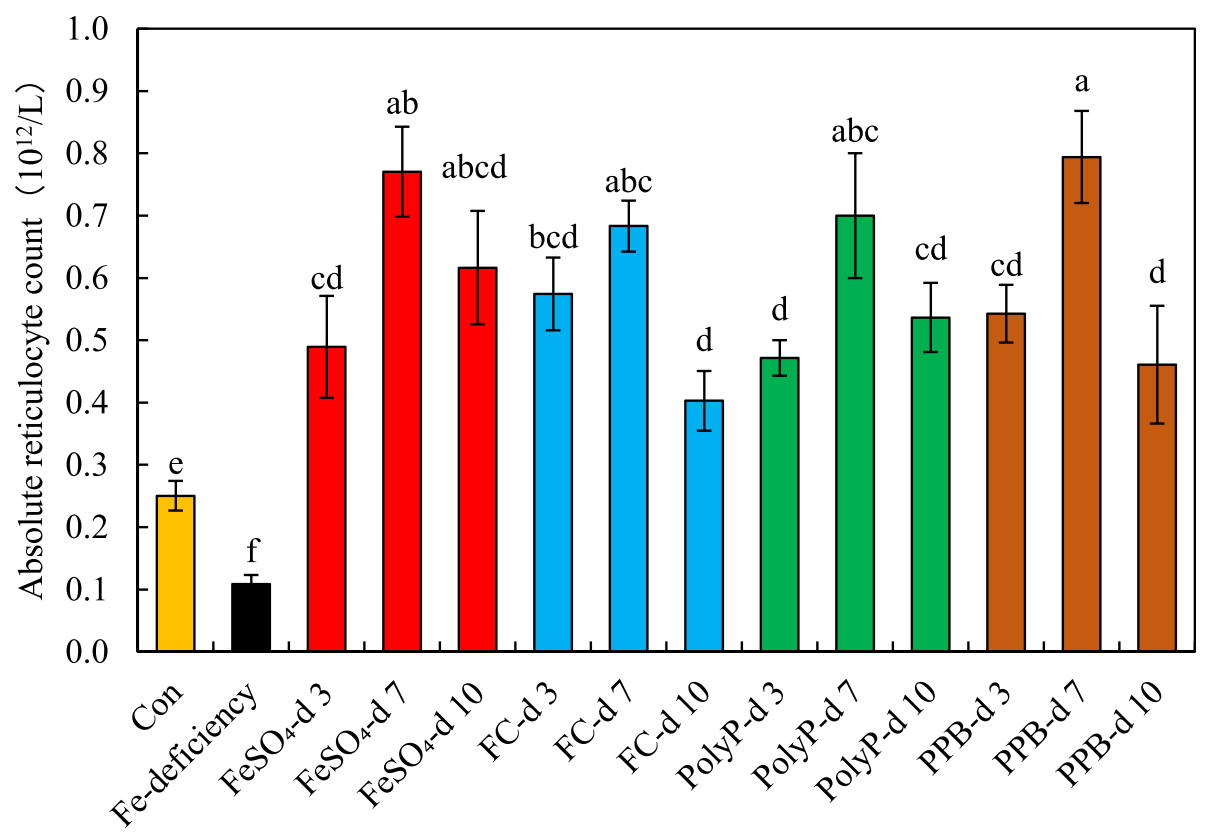

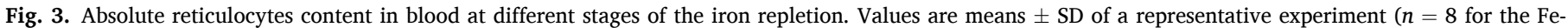
deficiency group; $n=6$ for the Con group; $n=4$ for other groups). Bars with different letters are significantly different (p $<0.05$ ).

iron in FC (34.2\%) and PolyP (26.4\%) groups from day 3 to day 10 were lower than those in PPB and $\mathrm{FeSO}_{4}$ groups $(\mathrm{p}<0.05)$. The final spleen iron in FC and PolyP group was $72.5 \%$ and $69.8 \%$, respectively, as that in Con group. Compared to liver, spleen has the priority in iron storage. Wang et al. (2014) reported the effect of squid ink melanin-Fe, $\mathrm{FeCl}_{3}$ and $\mathrm{FeSO}_{4}$ on iron-deficiency anemia treatment. They found the liver and spleen iron recovered to the normal level after 3 weeks' iron repletion. The intervention period was longer and the initial $\mathrm{Hb}$ content (85.1-86.1 g/L) was higher in their study than these in the present study. The physiological changes, such as reticulocyte $\mathrm{Hb}$ content, absolute reticulocyte content, liver and spleen iron, at different intervention time showed clearly how different iron supplements improved iron-deficiency anemia.

\subsection{The intestinal iron species analysis}

The total soluble intestinal iron in PPB was the highest, which was 98.4\% higher than that in FC group and $42.6 \%$ higher than that in PolyP group (Table $3 ; \mathrm{p}<0.05$ ). In addition, the LMW iron in PPB group was higher than these in other groups $(\mathrm{p}<0.05)$. Moreover, the nanosized 


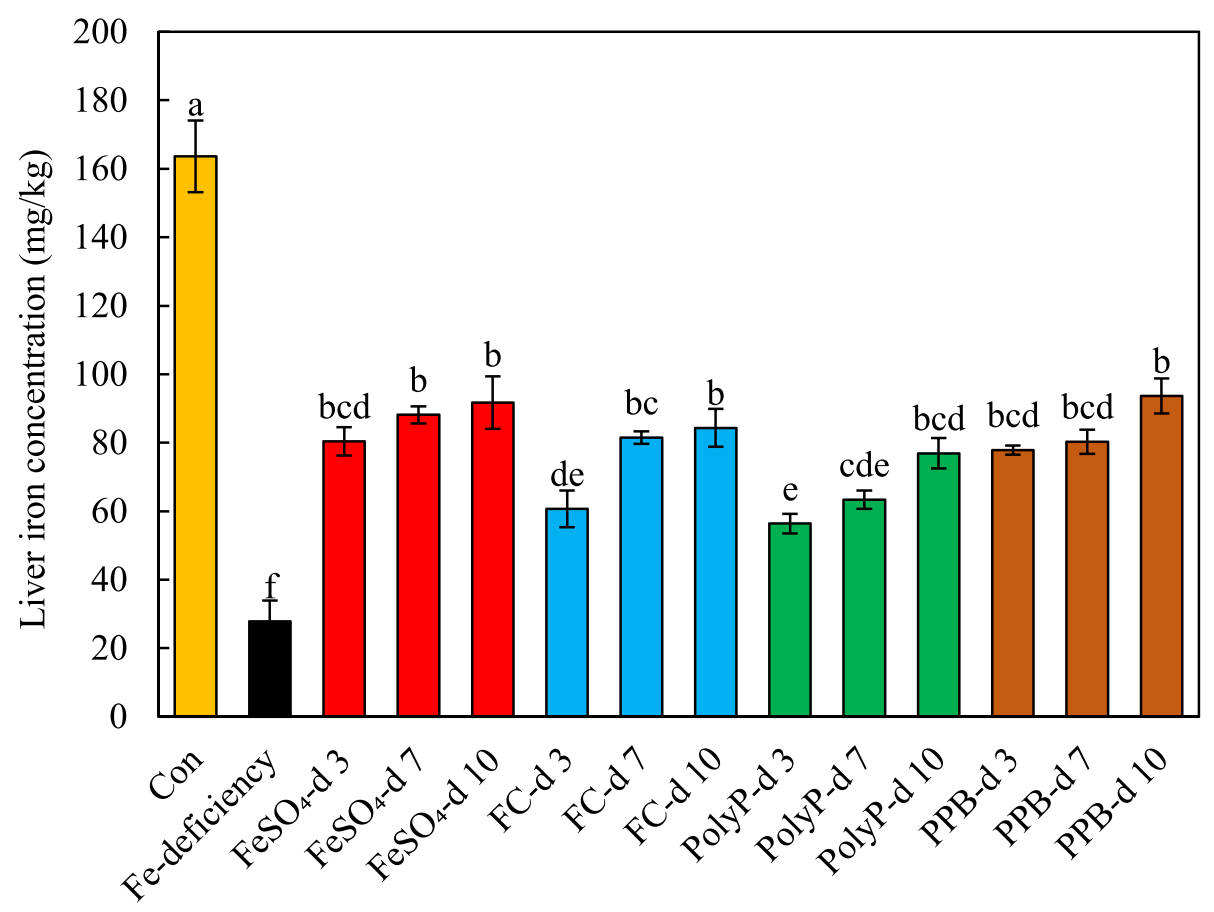

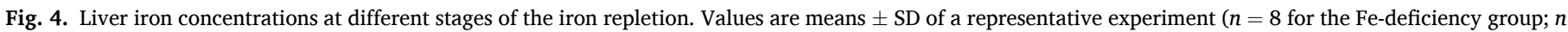
$=6$ for the Con group; $n=4$ for other groups). Bars with different letters are significantly different ( $<<0.05)$.

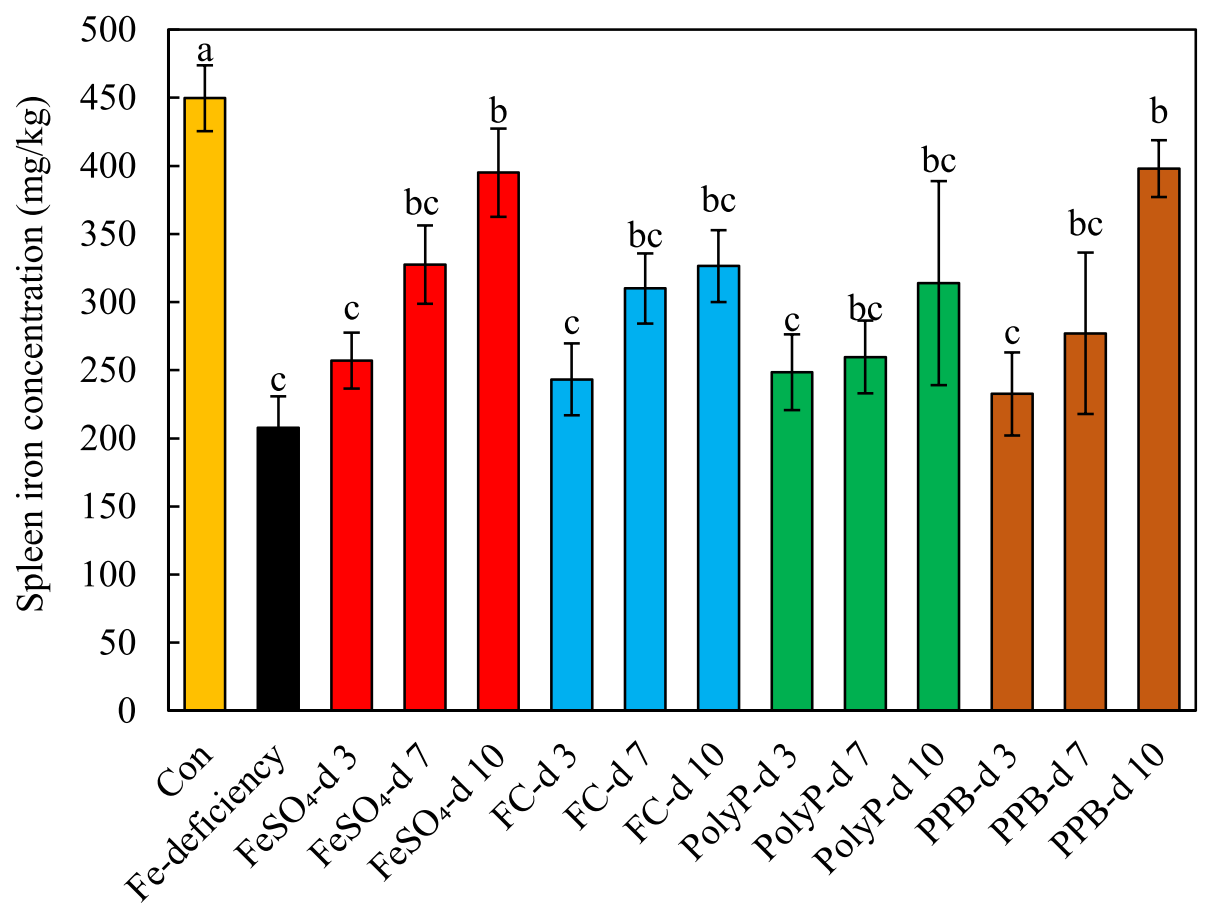

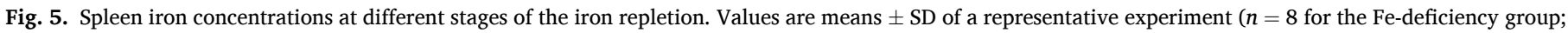
$n=6$ for the Con group; $n=4$ for other groups). Bars with different letters are significantly different ( $<<0.05)$.

iron fraction was the highest in PPB group, which was 53.0\% higher than that in FC group and $39.3 \%$ higher than that in PolyP group. Overall, PPB supplied more soluble, LMW iron and nanosized iron.

Nanosized particles can be absorbed as a whole particle by intestinal villus; therefore, have a higher utilization efficiency (Gao et al., 2018). For instance, Feng et al. (2018) reported that PPB could be absorbed and transported by polarized Caco-2 cell monolayers. Wu et al. (2014) prepared nanosized ferric hydrolysis products using muscle protein from Engraulis japonicus and tested the enhancement of non-heme iron absorption. They found those nanosized products can be absorbed by Caco- 2 cells and resulted in a higher total soluble and nanosized iron in intestinal content in rats. All these results indicated the feasibility for 
Table 3

Intestinal iron species analysis.

\begin{tabular}{llll}
\hline \multirow{2}{*}{ Group } & \multicolumn{3}{l}{ Percentage contents of intestinal iron species \% } \\
\cline { 2 - 4 } & ${\text { Total soluble } \text { iron }^{\mathrm{a}}}$ & LMW iron $^{\mathrm{b}}$ & Nanosized iron $^{\mathrm{c}}$ \\
\hline $\mathrm{Con}$ & $43.0 \pm 7.06^{\mathrm{c}}$ & $15.3 \pm 5.87^{\mathrm{bc}}$ & $27.7 \pm 2.41^{\mathrm{bc}}$ \\
$\mathrm{FeSO}_{4}$ & $51.9 \pm 9.04^{\mathrm{ab}}$ & $16.9 \pm 0.990^{\mathrm{bc}}$ & $35.0 \pm 2.80^{\mathrm{a}}$ \\
$\mathrm{FC}$ & $32.2 \pm 7.12^{\mathrm{c}}$ & $7.80 \pm 3.83^{\mathrm{c}}$ & $24.4 \pm 3.41^{\mathrm{c}}$ \\
PolyP & $44.8 \pm 6.32^{\mathrm{bc}}$ & $17.9 \pm 3.04^{\mathrm{bc}}$ & $26.8 \pm 3.40^{\mathrm{bc}}$ \\
PPB & $63.9 \pm 6.28^{\mathrm{a}}$ & $26.6 \pm 5.82^{\mathrm{a}}$ & $37.3 \pm 4.63^{\mathrm{a}}$ \\
\hline
\end{tabular}

Note: Values are means \pm SD of a representative experiment. Means with different letters are significantly different $(\mathrm{p}<0.05)$. a: Iron content in $0.22 \mu \mathrm{m}$ filtrate; b: Iron content in $3 \mathrm{kDa}$ filtrate; c: Calculated by subtraction of LMW iron from total soluble iron.

developing nanosized partials in mineral fortification.

Besides the function in iron-deficiency anemia treatment, nanosized iron has therapeutic applications including treatment of neuro-AIDS, cancer, blood contamination, Alzheimer's disease and Parkinson's disease (Alphandéry, 2020c). For instance, bio-synthesized iron oxide nanoparticles produced by magnetotactic bacteria showed promising anti-tumor activity on mice, RG-2 and GL-261 glioblastoma cells without any observable side effects, possibly due to the moderate heating temperatures reached during treatment and to bio-compatibility of nanoparticles (Alphandéry, 2020b; Mandawala et al., 2017). The biocompatibility, heating and organization properties of these iron oxide nanoparticles make them good candidates for tumor treatment, opened new possibilities in developing nanoparticles for medical applications (Hamdous et al., 2017).

In the present study, PPB was confirmed as novel iron supplements. The effect of PPB on iron-deficiency anemia was identical to gold iron standard $\left(\mathrm{FeSO}_{4}\right)$ and better than $\mathrm{FC}$ and PolyP. Compared to synthetic iron supplemental particles, PPB are natural nanosized particles present in many microorganisms, including microalgae. It is promising to produce functional nanoparticles using microorganism due to the high productivity and good biocompatibility. For instance, magnetotactic bacteria can be used in magnetosome (a nanoparticle) production for cancer treatment (Alphandéry, 2020a). Microalgae are considered one of the most promising feedstocks for sustainable production of food, feed, chemicals, materials and fuels (Draaisma et al., 2013). PPB are able to be produced by microalgal cell factories in large scale (Gao et al., 2018).

The digestive utilization of $\mathrm{P}, \mathrm{Ca}$ and $\mathrm{Mg}$ was also affected in irondeficient conditions (Pallarés et al., 1993), meaning people are likely to have multiple nutrient elements deficiency problems at the same time. Multi-mineral formulation supplies an option to solve this problem. Although only iron supplementation was focused in the present study, PPB are also carriers of other mineral elements, such as Ca (Yongmei Li et al., 2014), Mg (Yueyun Li et al., 2019), and Zn (Andrade et al., 2004), opening new possibilities to develop PPB as a novel multi-mineral nutrition enhancer. We reported the effect of whole microalgal cells as iron supplements on iron-deficiency anemia treatment in rats (Gao et al., 2019). However, the digestive efficiency of microalgal cells is low due to the presence of a cell wall. In addition, the colour and taste of microalgae are difficult to be accepted by some people. Hence, microalgal compounds extraction and processing are important for commercial applications. PPB could be considered as a potential commercial product from microalgae for iron deficiency treatment.

\section{Conclusions}

In the present study, the effects of four iron supplements on iron deficiency treatment were investigated at three intervention stages (i.e. day 3, 7 and 10). The Hb improvements were similar in all iron repletion groups at day 3 and day 7. However, PPB resulted in a higher $\mathrm{Hb}$ regeneration efficiency at day 10 . PPB diet supplied more intestinal total soluble iron, LMW and nanosized iron than FC and PolyP diets. This study not only provided evidence for developing PPB as novel iron supplements for iron-deficiency anemia treatment, but also opened new possibilities in high-value products production using microalgal cell factories.

\section{Declaration of competing interest}

The authors confirm that they have no conflicts of interest with respect to the work described in this manuscript.

\section{CRediT authorship contribution statement}

Fengzheng Gao: Investigation, Methodology, Formal analysis, Data curation, Software, Visualization, Writing - original draft, Writing - review \& editing. Yu Miao: Investigation, Formal analysis, Data curation, Writing - review \& editing. Wei Guo: Investigation, Formal analysis, Data curation, Writing - review \& editing. Mingyong Zeng: Project administration, Formal analysis, Funding acquisition, Methodology, Supervision, Writing - review \& editing.

\section{Acknowledgments}

This work has been funded by the following grants: Technology development projects of Shandong province, China [grant number 20120132110022]; The Ph.D. Programs Foundation of Ministry of Education of. China [grant number 2013GHY11536]. The first author would like to thank China Scholarship Council (CSC, China) for financial support for his two-year research in Wageningen University (The Netherlands) [grant number 201706330062]. The authors would like to thank Professor Jindong Zhao from the Institute of Hydrobiology, Chinese Academy of Sciences, for his help in Synechococcus sp. PCC 7002 donation and Professor Tianzhong Liu and Lin Chen from Qingdao Institute of Bioenergy and Bioprocess Technology, Chinese Academy of Sciences for their help in microalgae large-scale cultivation.

\section{References}

Alenkina, I. V., Vinogradov, A. V., Felner, I., Konstantinova, T. S., Kuzmann, E., Semionkin, V. A., \& Oshtrakh, M. I. (2019). The iron state in spleen and liver tissues from patients with hematological malignancies studied using magnetization measurements and mössbauer spectroscopy. Cell Biochemistry and Biophysics, 77(1), 33-46. https://doi.org/10.1007/s12013-018-0855-4

Alférez, M. J. M., Daz-Castro, J., Lpez-Aliaga, I., Rodrguez-Ferrer, M., PérezSánchez, L. J., \& Campos, M. S. (2011). Development of nutritional iron deficiency in growing male rats: Haematological parameters, iron bioavailability and oxidative defence. British Journal of Nutrition, 105(4), 517-525. https://doi.org/10.1017/ S0007114510004046

Alphandéry, E. (2019). Biodistribution and targeting properties of iron oxide nanoparticles for treatments of cancer and iron anemia disease. Nanotoxicology. https://doi.org/10.1080/17435390.2019.1572809

Alphandéry, E. (2020a). Applications of magnetotactic bacteria and magnetosome for cancer treatment: A review emphasizing on practical and mechanistic aspects. Drug Discovery Today. https://doi.org/10.1016/j.drudis.2020.06.010

Alphandéry, E. (2020b). Bio-synthesized iron oxide nanoparticles for cancer treatment. International Journal of Pharmaceutics, 586(June), Article 119472. https://doi.org/ 10.1016/j.ijpharm.2020.119472

Alphandéry, E. (2020c). Iron oxide nanoparticles for therapeutic applications. Drug Discovery Today, 25(1), 141-149. https://doi.org/10.1016/j.drudis.2019.09.020

Alphandéry, E. (2020d). Natural metallic nanoparticles for application in nano-oncology. International Journal of Molecular Sciences. https://doi.org/10.3390/ijms21124412

Andrade, L., Keim, C. N., Farina, M., \& Pfeiffer, W. C. (2004). Zinc detoxification by a cyanobacterium from a metal contaminated bay in Brazil. Brazilian Archives of Biology and Technology, 47(1), 147-152. https://doi.org/10.1590/S151689132004000100020

Block, G. A., Fishbane, S., Rodriguez, M., Smits, G., Shemesh, S., Pergola, P. E., Wolf, M., \& Chertow, G. M. (2015). A 12-week, double-blind, placebo-controlled trial of ferric citrate for the treatment of iron deficiency anemia and reduction of serum phosphate in patients with CKD stages 3-5. American Journal of Kidney Diseases, 65(5), 728-736. https://doi.org/10.1053/j.ajkd.2014.10.014 
Bries, A. E., Wang, C., Agbemafle, I., Wels, B., \& Reddy, M. B. (2019). Assessment of acute serum, non-transferrin bound iron and gastrointestinal symptoms with 3-week consumption with iron-enriched Aspergillus oryzae compared to ferrous sulfate. Current Developments in Nutrition, 5, 1-7. https://doi.org/10.1093/cdn/nzz127

Camaschella, C. (2015). Iron-deficiency anemia. New England Journal of Medicine, 372 (19), 1832-1843. https://doi.org/10.1056/NEJMra1401038

Chaud, M. V., Izumi, C., Nahaal, Z., Shuhama, T., Pires Bianchi, M. D. L., \& De Freitas, O. (2002). Iron derivatives from casein hydrolysates as a potential source in the treatment of iron deficiency. Journal of Agricultural and Food Chemistry, 50(4), 871-877. https://doi.org/10.1021/jf0111312

Clark, S. F. (2008). Iron deficiency anemia. Nutrition in Clinical Practice, 23(2), 128-141. https://doi.org/10.1177/0884533608314536

Draaisma, R. B., Wijffels, R. H., Slegers, P. M., Brentner, L. B., Roy, A., \& Barbosa, M. J. (2013). Food commodities from microalgae. Current Opinion in Biotechnology, 24(2), 169-177. https://doi.org/10.1016/j.copbio.2012.09.012

Ennis, K. M., Dahl, L. V., Rao, R. B., \& Georgieff, M. K. (2018). Reticulocyte hemoglobin content as an early predictive biomarker of brain iron deficiency. Pediatric Research, 84(5), 765-769. https://doi.org/10.1038/s41390-018-0178-6

Evcan, E., \& Gulec, S. (2020). The development of lentil derived protein-iron complexes and their effects on iron deficiency anemia: In vitro. Food and Function, 11(5), 4185-4192. https://doi.org/10.1039/d0fo00384k

Feng, G., Feng, Y., Guo, T., Yang, Y., Guo, W., Huang, M., Wu, H., \& Zeng, M. (2018). Biogenic polyphosphate nanoparticles from Synechococcus sp. PCC 7002 exhibit intestinal protective potential in human intestinal epithelial cells in vitro and murine small intestine ex vivo. Journal of Agricultural and Food Chemistry, 66(30), 8026-8035. https://doi.org/10.1021/acs.jafc.8b03381

Feng, G., Tang, S., Gang, Y., Zeng, M., \& Wu, H. (2020). Chondroitin sulfate and its nanocomposites with protamine or chitosan stabilize and deliver available nanosized iron. International Journal of Biological Macromolecules. https://doi.org/10.1016/j. ijbiomac.2020.02.103

Feng, G., Zeng, M., Huang, M., Zhu, S., Guo, W., \& Wu, H. (2019). Protective effect of biogenic polyphosphate nanoparticles from: Synechococcus sp. PCC 7002 on dextran sodium sulphate-induced colitis in mice. Food and Function, 10(2), 1007-1016. https://doi.org/10.1039/c8fo01861h

Gao, F., Guo, W., Zeng, M., Feng, Y., \& Feng, G. (2019). Effect of microalgae as iron supplements on iron-deficiency anemia in rats. Food and Function, 10(2), 723-732. https://doi.org/10.1039/c8fo01834k

Gao, F., Wu, H., Zeng, M., Huang, M., \& Feng, G. (2018). Overproduction, purification, and characterization of nanosized polyphosphate bodies from Synechococcus sp. PCC 7002. Microbial Cell Factories, 17(1), 1-12. https://doi.org/10.1186/s12934. 018-0870-6

Gastroenterol, J. P., Author, N., May, P. M. C., Syed, S., Kugathasan, S., Kumar, A., Prince, J., Schoen, B. T., Mccracken, C., Ziegler, T. R., \& Suchdev, P. S. (2018). HHS public access author manuscript iron deficiency in children with inflammatory bowel disease. https://doi.org/10.1097/MPG.0000000000001335.Use, 64, 5, 713720 .

Gezgin Yıldırım, D., Kaya, Z., \& Bakkaloglu, S. A. (2019). Utility of new red cell parameters for distinguishing functional iron deficiency from absolute iron deficiency in children with familial Mediterranean fever. The International Journal of Literary Humanities, 41(2), 293-297. https://doi.org/10.1111/ijlh.12971

Hamdous, Y., Chebbi, I., Mandawala, C., Le Fèvre, R., Guyot, F., Seksek, O., \& Alphandéry, E. (2017). Biocompatible coated magnetosome minerals with various organization and cellular interaction properties induce cytotoxicity towards RG-2 and GL-261 glioma cells in the presence of an alternating magnetic field. Journal of Nanobiotechnology. https://doi.org/10.1186/s12951-017-0293-2

Hilty, F. M., Arnold, M., Hilbe, M., Teleki, A., Knijnenburg, J. T. N., Ehrensperger, F., Hurrell, R. F., Pratsinis, S. E., Langhans, W., \& Zimmermann, M. B. (2010). Iron from nanocompounds containing iron and zinc is highly bioavailable in rats without tissue accumulation. Nature Nanotechnology, 5(5), 374-380. https://doi.org/10.1038/ nnano. 2010.79

Kassebaum, N. J., Jasrasaria, R., Naghavi, M., Wulf, S. K., Johns, N., Lozano, R., Regan, M., Weatherall, D., Chou, D. P., Eisele, T. P., Flaxman, S. R., Pullan, R. L., Brooker, S. J., \& Murray, C. J. L. (2015). Plenary Paper RED CELLS , IRON , AND ERYTHROPOIESIS A systematic analysis of global anemia burden from 1990 to 2010. Blood Journal, 123(5), 615-625. https://doi.org/10.1182/blood-2013-06508325

Lei, X. G., Weaver, J. D., Mullaney, E., Ullah, A. H., \& Azain, M. J. (2013). Phytase, a new life for an "old" enzyme. Annual Review of Animal Biosciences, 1(1), 283-309. https:// doi.org/10.1146/annurev-animal-031412-103717

Lesjak, M., Balesaria, S., Skinner, V., Debnam, E. S., \& Srai, S. K. S. (2019). Quercetin inhibits intestinal non-haem iron absorption by regulating iron metabolism genes in the tissues. European Journal of Nutrition, 58(2), 743-753. https://doi.org/10.1007/ s00394-018-1680-7

Li, Y., Rahman, S. M., Li, G., Fowle, W., Nielsen, P. H., \& Gu, A. Z. (2019). The composition and implications of polyphosphate-metal in enhanced biological phosphorus removal systems. Environmental Science and Technology. https://doi.org/ 10.1021/acs.est.8b06827

Li, Y., Zou, J., Zhang, L., \& Sun, J. (2014). Aerobic granular sludge for simultaneous accumulation of mineral phosphorus and removal of nitrogen via nitrite in wastewater. Bioresource Technology, 154, 178-184. https://doi.org/10.1016/j. biortech.2013.12.033

Ludwig, M., \& Bryant, D. A. (2011). Transcription profiling of the model cyanobacterium Synechococcus sp. Strain PCC 7002 by next-gen $\left(\mathrm{SOLiD}^{\mathrm{TM}}\right)$ sequencing of cDNA. Frontiers in Microbiology, 2(MAR), 1-23. https://doi.org/10.3389/fmicb.2011.00041

Lundeen, E. A., Lind, J. N., Clarke, K. E. N., Aburto, N. J., Imanalieva, C., Mamyrbaeva, T., Ismailova, A., Timmer, A., Whitehead, R. D., Praslova, L.,
Samohleb, G., Minbaev, M., Addo, O. Y., \& Serdula, M. K. (2019). Four years after implementation of a national micronutrient powder program in Kyrgyzstan, prevalence of iron deficiency and iron deficiency anemia is lower, but prevalence of vitamin A deficiency is higher. European Journal of Clinical Nutrition, 73(3), 416-423. https://doi.org/10.1038/s41430-018-0368-7

Mahoney, A. W., VanOrden, C. C., \& Hendricks, D. G. (1974). Efficiency of converting food iron into hemoglobin by the anemic rat. Nutrition and Metabolism. https://doi. org/10.1159/000175540

Ma, X., Liu, C., Song, W., Che, S., Wang, C., Feng, X., Li, B., \& Dai, Y. (2019). Evaluating the efficacy of a ferrous-ion-chelating peptide from Alaska pollock frame for the improvement of iron nutritional status in rats. Food and Function, 10(8), 4888-4896. https://doi.org/10.1039/c9fo00310j

Mandawala, C., Chebbi, I., Durand-Dubief, M., Le Fèvre, R., Hamdous, Y., Guyot, F., \& Alphandéry, E. (2017). Biocompatible and stable magnetosome minerals coated with poly-l-lysine, citric acid, oleic acid, and carboxy-methyl-dextran for application in the magnetic hyperthermia treatment of tumors. Journal of Materials Chemistry B. https://doi.org/10.1039/c6tb03248f

McLean, E., Cogswell, M., Egli, I., Wojdyla, D., \& De Benoist, B. (2009). Worldwide prevalence of anaemia, WHO vitamin and mineral nutrition information system, 19932005. Public Health Nutrition. https://doi.org/10.1017/S1368980008002401

Pallarés, I., Lisbona, F., Aliaga, I. L., Barrionuevo, M., Alférez, M. J. M., \& Campos, M. S. (1993). Effect of iron deficiency on the digestive utilization of iron, phosphorus, calcium and magnesium in rats. British Journal of Nutrition, 70(2), 609-620. https:// doi.org/10.1079/bjn19930152

Parodi, E., Giraudo, M. T., Ricceri, F., Aurucci, M. L., Mazzone, R., \& Ramenghi, U. (2016). Absolute reticulocyte count and reticulocyte hemoglobin content as predictors of early response to exclusive oral iron in children with iron deficiency anemia. Anemia. https://doi.org/10.1155/2016/7345835, 2016.

Penen, F., Malherbe, J., Isaure, M. P., Dobritzsch, D., Bertalan, I., Gontier, E., Le Coustumer, P., \& Schaumlöffel, D. (2016). Chemical bioimaging for the subcellular localization of trace elements by high contrast TEM, TEM/X-EDS, and NanoSIMS. Journal Of Trace Elements In Medicine And Biology. https://doi.org/10.1016/j. jtemb.2016.04.014

Pietrangelo, A. (2016). Iron and the liver. Liver International, 36(November 2015), 116-123. https://doi.org/10.1111/liv.13020

Pritwani, R., \& Mathur, P. (2015). Strategies to combat micronutrient deficiencies: A review. International Journal of Health Sciences \& Research, 5(2), 362-373.

Rahmatollah, D., Farzinpour, A., Vaziry, A., \& Sadeghi, G. (2018). Effect of replacing dietary FeSO4 with cysteine-coated $\mathrm{Fe} 3 \mathrm{O} 4$ nanoparticles on quails. Italian Journal of Animal Science, 17(1), 121-127. https://doi.org/10.1080/1828051X.2017.1345662

Rahn-Lee, L., \& Komeili, A. (2013). The magnetosome model: Insights into the mechanisms of bacterial biomineralization. Frontiers in Microbiology, 4(NOV), 1-8. https://doi.org/10.3389/fmicb.2013.00352

Ruiz, F. A., Marchesini, N., Seufferheld, M., Govindjee, \& Docampo, R. (2001). The polyphosphate bodies of Chlamydomonas reinhardtii possess a proton-pumping pyrophosphatase and are similar to acidocalcisomes. Journal of Biological Chemistry, 276(49), 46196-46203. https://doi.org/10.1074/jbc.M105268200

Segawa, S., Fujiya, M., Konishi, H., Ueno, N., Kobayashi, N., Shigyo, T., \& Kohgo, Y. (2011). Probiotic-Derived polyphosphate enhances the epithelial barrier function and maintains intestinal homeostasis through integrin-p38 MAPK pathway. PloS One, 6(8). https://doi.org/10.1371/journal.pone.0023278

Sharma, A., Shilpa Shree, B. G., Arora, S., \& Kapila, S. (2017). Preparation of lactose-iron complex and its cyto-toxicity, in-vitro digestion and bioaccessibility in Caco-2 cell model system. Food Bioscience. https://doi.org/10.1016/j.fbio.2017.10.001

Shrimpton, R., \& Schultink, W. (2002). Can supplements help meet the micronutrient needs of the developing world? Proceedings of the Nutrition Society, 61(2), 223-229. https://doi.org/10.1079/pns2002163

Shults, G. W., \& Wierbicki, E. (1973). EFFECTS OF SODIUM CHLORIDE AND CONDENSED PHOSPHATES ON THE WATER-HOLDING CAPACITY, pH AND SWELLING OF CHICKEN MUSCLE. Journal of Food Science, 38(6), 991-994. https:// doi.org/10.1111/j.1365-2621.1973.tb02131.x

Stevens, G. A., Finucane, M. M., De-Regil, L. M., Paciorek, C. J., Flaxman, S. R. Branca, F., Peña-Rosas, J. P., Bhutta, Z. A., \& Ezzati, M. (2013). Global, regional, and national trends in haemoglobin concentration and prevalence of total and severe anaemia in children and pregnant and non-pregnant women for 1995-2011: A systematic analysis of population-representative data. The Lancet Global Health, 1(1), 16-25. https://doi.org/10.1016/S2214-109X(13)70001-9

Wang, T., Lin, S., Cui, P., Bao, Z., Liu, K., Jiang, P., Zhu, B., \& Sun, N. (2020). Antarctic krill derived peptide as a nanocarrier of iron through the gastrointestinal tract. Food Bioscience. https://doi.org/10.1016/j.fbio.2020.100657

Wang, K., Li, L., Xu, X., Lu, L., Wang, J., Wang, S., Wang, Y., Jin, Z., Zhang, J. Z., \& Jiang, Y. (2019). Fe 304 @ Astragalus polysaccharide core-shell nanoparticles for iron deficiency anemia therapy and magnetic resonance imaging in vivo. ACS Applied Materials and Interfaces, 11(11), 10452-10461. https://doi.org/10.1021, acsami.8b18648

Wang, F. R., Xie, Z. G., Ye, X. Q., Deng, S. G., Hu, Y. Q., Guo, X., \& Chen, S. G. (2014). Effectiveness of treatment of iron deficiency anemia in rats with squid ink melaninFe. Food and Function, 5(1), 123-128. https://doi.org/10.1039/c3fo60383k

Wijffels, R. H., \& Barbosa, M. J. (2010). An outlook on microalgal biofuels. In Science. https://doi.org/10.1126/science.1189003

Wu, H., Zhu, S., Zeng, M., Liu, Z., Dong, S., Zhao, Y., Huang, H., \& Lo, Y. M. (2014). Enhancement of non-heme iron absorption by anchovy (Engraulis japonicus) muscle protein hydrolysate involves a nanoparticle-mediated mechanism. Journal of Agricultural and Food Chemistry, 62(34), 8632-8639. https://doi.org/10.1021/ jf5018719 
Wu, L., Zou, Y., Miao, Y., Zhang, J., Zhu, S., Zeng, M., \& Wu, H. (2019). Dietary gelatin enhances non-heme iron absorption possibly via regulation of systemic iron homeostasis in rats. Journal of Functional Foods, 59(January), 272-280. https://doi org/10.1016/j.jff.2019.06.005
Zhou, Y., Lisowski, W., Zhou, Y., Jern, N. W., Huang, K., \& Fong, E. (2017). Genetic improvement of Magnetospirillum gryphiswaldense for enhanced biological removal of phosphate. Biotechnology Letters. https://doi.org/10.1007/s10529-017-2383-5 Zimmermann, M. B., \& Hurrell, R. F. (2007). Nutritional iron deficiency. Lancet, 370 (9586), 511-520. https://doi.org/10.1016/S0140-6736(07)61235-5 